\title{
Terminal Schwann Cells Participate in Neuromuscular Synapse Remodeling during Reinnervation following Nerve Injury
}

\author{
Hyuno Kang, ${ }^{1,2 \star}$ Le Tian, ${ }^{1 \star}$ Michelle Mikesh, ${ }^{1}$ Jeff W. Lichtman, ${ }^{2}$ and Wesley J. Thompson ${ }^{3}$ \\ ${ }^{1}$ Section of Molecular Cell and Developmental Biology, The University of Texas at Austin, Texas 78712, ${ }^{2}$ Department of Molecular and Cellular Biology and \\ Center for Brain Science, Harvard University, Cambridge, Massachusetts 02138, and ${ }^{3}$ Department of Biology, Texas A\&M University, College Station, Texas \\ 77843
}

Schwann cells (SCs) at neuromuscular junctions (NMJs) play active roles in synaptic homeostasis and repair. We have studied how SCs contribute to reinnervation of NMJs using vital imaging of mice whose motor axons and SCs are transgenically labeled with different colors of fluorescent proteins. Motor axons most commonly regenerate to the original synaptic site by following SC-filled endoneurial tubes. During the period of denervation, SCs at the NMJ extend elaborate processes from the junction, as shown previously, but they also retract some processes from territory they previously occupied within the endplate. The degree of this retraction depends on the length of the period of denervation. We show that the topology of the remaining SC processes influences the branching pattern of regenerating axon terminals and the redistribution of acetylcholine receptors (AChRs). Upon arriving at the junction, regenerating axons follow existing SC processes within the old synaptic site. Some of the AChR loss that follows denervation is correlated with failure of portions of the old synaptic site that lack SC coverage to be reinnervated. New AChR clustering is also induced by axon terminals that follow SC processes extended during denervation. These observations show that SCs participate actively in the remodeling of neuromuscular synapses following nerve injury by their guidance of axonal reinnervation.

Key words: glial cell; nerve injury; neuromuscular junction; regeneration; synaptic plasticity; synaptic structure

\section{Introduction}

Fluorescent labeling of motor axon terminals and postsynaptic acetylcholine receptors (AChRs) at the neuromuscular junction $(\mathrm{NMJ})$ has been used to repeatedly image these synapses in living mice and examine how they change over the lifetime of these animals (Rich and Lichtman, 1989; Nguyen et al., 2002; Zuo et al., 2004). NMJs in young adult animals (1-12 months old) are remarkably stable in their structure (Balice-Gordon and Lichtman, 1990). However, there are several circumstances in which the structure of these synapses changes dramatically: during early development (Balice-Gordon and Lichtman, 1993; Marques et al., 2000), aging (Valdez et al., 2010; Li et al., 2011), disease (Blake et al., 2002; Schaefer et al., 2005; Serra et al., 2012), and reinnervation (Rich and Lichtman, 1989). When motor neurons are disconnected from their muscle fibers by injury to a peripheral

\footnotetext{
Received Nov. 4, 2013; revised Feb. 27, 2014; accepted March 18, 2014.

Author contributions: H.K., L.T., M.M., J.W.L., and W.J.T. designed research; H.K., L.T., and M.M. performed research; H.K., L.T., J.W.L., and W.J.T. analyzed data; H.K., L.T., M.M., J.W.L., and W.J.T. wrote the paper.

This research was funded by National Institutes of Health (NS20480). We thank M. Rimer, D.I. Lee, and I.W. Smith for their critiques of this manuscript.

${ }^{*}$ H.K. and L.T. contributed equally to this work.

The authors declare no competing financial interests.

Correspondence should be addressed to Wesley J. Thompson, Department of Biology, Texas A\&M University,

College Station, TX 77843-3474. E-mail: wthompson@bio.tamu.edu.

L.T.'s present address: Han Santos Ringer, PLLC, Seattle WA 98057.

DOI:10.1523/JNEUROSCI.4673-13.2014

Copyright $\odot 2014$ the authors $\quad 0270-6474 / 14 / 346323-11 \$ 15.00 / 0$
}

nerve, they frequently regenerate and reconnect with muscle fibers, at least in adult rodents. The regenerating axons normally follow the endoneurial tubes (a.k.a. "Schwann cell tubes") that they previously occupied (Nguyen et al., 2002). When axons arrive back at the synaptic sites, there is frequently a remodeling of these contacts. The degree of this remodeling depends on how quickly the sites are reinnervated. Rapid reinnervation leads to modest remodeling whereas as delayed reinnervation results in more profound changes in the synaptic site (Rich and Lichtman, 1989).

A major question in all these instances of remodeling is how much of the structural change is initiated by a loss of postsynaptic AChRs. It is quite clear that such loss can occur as a consequence of differential activity among individual terminals at a single synaptic site (Balice-Gordon and Lichtman, 1994). This mechanism could account for synaptic remodeling.

There is another cellular component at the NMJ that could play a role in the stability of the synaptic connection, i.e., the glial (Schwann cell, SC) coverings of the motor nerve terminal (Sanes and Lichtman, 1999; Zuo et al., 2004; Ko et al., 2007). In the adult animal, the terminal SCs (tSCs) extend processes away from the old synaptic site upon denervation (Reynolds and Woolf, 1992), and these processes provide a substrate that leads regenerating axons to vacant synaptic sites and leads them to sprout beyond these sites (Son and Thompson, 1995). However, to what degree these SCs influence how the old synaptic sites are reoccupied during reinnervation is unknown. Here we have explored this 
issue by detailed examination of reinnervation by use of both axon and SC labeling in vivo. We found that regenerating axons are guided by tSC processes within the denervated synaptic site. However, tSCs responding to denervation gradually abandon portions of the synaptic site and some of these abandoned sites are never reinnervated. The lack of reinnervation of these sites and the reinnervation of others leads to loss of AChRs at the unreinnervated sites. Thus, these results show that a considerable fraction of the remodeling of synaptic sites is correlated with changes in SC coverage of synaptic sites during the period of denervation.

\section{Materials and Methods \\ Transgenic mice}

Two lines of double transgenic mice were used in most of experiments. The most commonly used line expressed cytoplasmic cyan fluorescent protein (CFP) driven by the thy-1 promoter in motor neurons, CFP line 23 (Feng et al., 2000), and enhanced green fluorescent protein (EGFP) driven by the S100 promoter in SCs (Zuo et al., 2004). A second line expressed CFP as above and in addition EGFP driven by the nestin promoter and its neural enhancer (Mignone et al., 2004). Nestin-GFP mice mirror the expression of nestin itself in SCs: nestin is undetectable by immunostaining in SCs in intact nerves and tSCs at innervated junctions, but is rapidly upregulated in these cells following denervation (Kang et al., 2007). We used the S100-GFP line for the experiments in which we desired SC images before the denervation (Figs. $1 A, B, 4,5 A, B, 6,8$ ). Otherwise, we used nestin-GFP animals (Figs. $2 A-C, 3 A, B, 7 A, B$ ) because of the brighter GFP signals in SCs. Mice were genotyped by observing the presence of CFP-labeled axons in the ear skin (thy-1-CFP), the GFP in the lens of the eyes (S100-GFP), and GFP in hair follicles (nestinGFP) under a fluorescence dissecting scope (Zuo et al., 2004; Kang et al., 2007).

\section{Surgery and denervation}

Young adult mice (2-4 months of age, both sexes) were anesthetized with ketamine/xylazine (K/X; $0.10-0.15 \mathrm{ml}$ of a $0.9 \% \mathrm{NaCl}$ solution containing $17.4 \mathrm{mg} / \mathrm{ml}$ ketamine and $2.6 \mathrm{mg} / \mathrm{ml}$ xylazine). A maintenance dose $(0.05 \mathrm{ml}$ of $\mathrm{K} / \mathrm{X}$ mixture $)$ was administered as necessary to maintain anesthesia.

Sternomastoid muscle. In experiments using the sternomastoid, the anesthetized animal was placed in the supine position on a magnetic steel plate with the incisors of the upper jaw and limbs secured with rubber bands attached to magnets. Hair over the surface of the neck was removed with a depilatory. To expose the sternomastoid muscle, the submandibular salivary gland and the fat pad were retracted laterally after a ventral midline incision through the skin of the neck. To vary the time before reinnervation, we used three different denervation methods following methods initially used by Rich and Lichtman (1989). The fastest reinnervation (junctions begin to reform at $4 \mathrm{~d}$ ) was achieved following crush of the muscle nerve with \#5 Dumont forceps just lateral to the muscle (lateral nerve crush). To delay reinnervation, we either crushed the nerve $\sim 6 \mathrm{~mm}$ away from the muscle (medial nerve crush; junctions begin to reform $6 \mathrm{~d}$ later), or crushed the nerve twice (double nerve crush) at the medial site, the second crush following the first before the regenerating axons had reached the muscle (i.e., after $5 \mathrm{~d}$ ). Reinnervation of the muscle following double nerve crush began $\sim 9 \mathrm{~d}$ after the first crush. The wound was closed with 6-0 suture. These procedures for denervation were accomplished using the exact same surgery that was used at later times for repetitive vital imaging and the same procedures used by us and others previously for such vital imaging in the absence of denervation. As no changes in the morphology of junctions have been seen from this kind of surgery before, we attribute the changes we report here to the effects of denervation. It is unlikely that the effects of longer periods of denervation from the double nerve crush are the result of re-injury of nerves within the junctions as no reinnervation had begun at the time of the second nerve crush.

Soleus muscle. In experiments using the soleus muscle, the anesthetized animal was placed in a prone position and secured to a plate as described
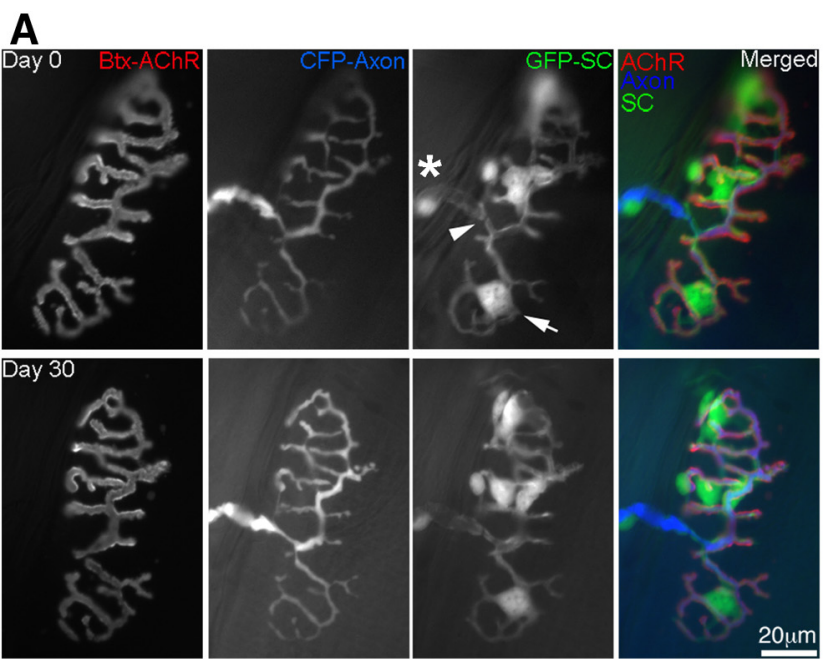

\section{B}
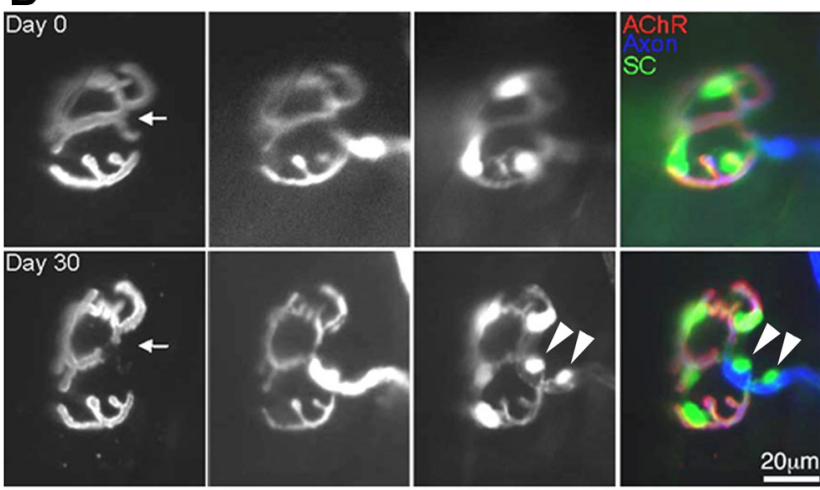

Figure 1. Repeated, vital images of two NMJs in the mouse sternomastoid muscle illustrate the stability of components of the junction. Transgenic expression of CFP (blue fluorescence) in motor axons and GFP (green fluorescence) in SCs (both the tSCs and the SCs myelinating the axon). The $A C h R s$ were labeled with a nonblocking concentration of Btx (red fluorescence). Two examples are shown $(\boldsymbol{A}, \boldsymbol{B})$ of junctions imaged two times, $30 \mathrm{~d}$ apart. The axon enters the synaptic site from the left $(\boldsymbol{A})$ or right $(\boldsymbol{B})$ and arborizes above pretzel-shaped $A C h R s$ in the muscle fiber. There are several SC bodies (round, brighter staining objects, one of which is indicated by the arrow in $\boldsymbol{A}$ ) that extend processes that cover the nerve terminal. The last hemi-node in $\boldsymbol{A}$ is visible where the axon enters the synaptic site (arrowhead). Both junctions show stable structures. $\boldsymbol{B}$, Example of relatively small change in a second junction occurring at the site of nerve entry. AChRs present at the first image are lost at the second. Interestingly, this change occurs at a site where a new SC body is present. The cell bodies marked with arrowheads have the appearance of myelinating cells (with a hollow tube of GFP labeling, see asterisk in $\boldsymbol{A}$ ), and a node between the arrowheads appears to be the site where the nerve branches to innervate the lower portion of the pretzel.

above. The right hindlimb was positioned with its lateral surface uppermost, hair was removed with a depilatory, and an incision made through the skin in the shank. To expose the soleus muscle, an incision was made through the fascia along the midline between the anterior and posterior compartments. The soleus muscle and its nerve were exposed by retracting the wound margins as well as the lateral gastrocnemius posteriorly. Denervation was accomplished by crushing the soleus nerve twice at a distance $1 \mathrm{~mm}$ from its entry into the muscle with \#5 Dumont forceps. The wound was then closed with 6-0 suture.

\section{Vital imaging}

Procedures for vital imaging in sternomastoid muscle were identical to those described previously (Zuo et al., 2004). Imaging of soleus was conducted using modifications of Wigston (1989) and Zuo et al. (2004). The soleus was exposed as described above for denervation and a small spatula was used to lift the soleus muscle. Postsynaptic AChRs were labeled by application of Alexa 594- or rhodamine-conjugated $\alpha$-bungarotoxin (Btx; $1 \mu \mathrm{g} / \mathrm{ml}$ in lactated Ringer's solution; Invitrogen) 

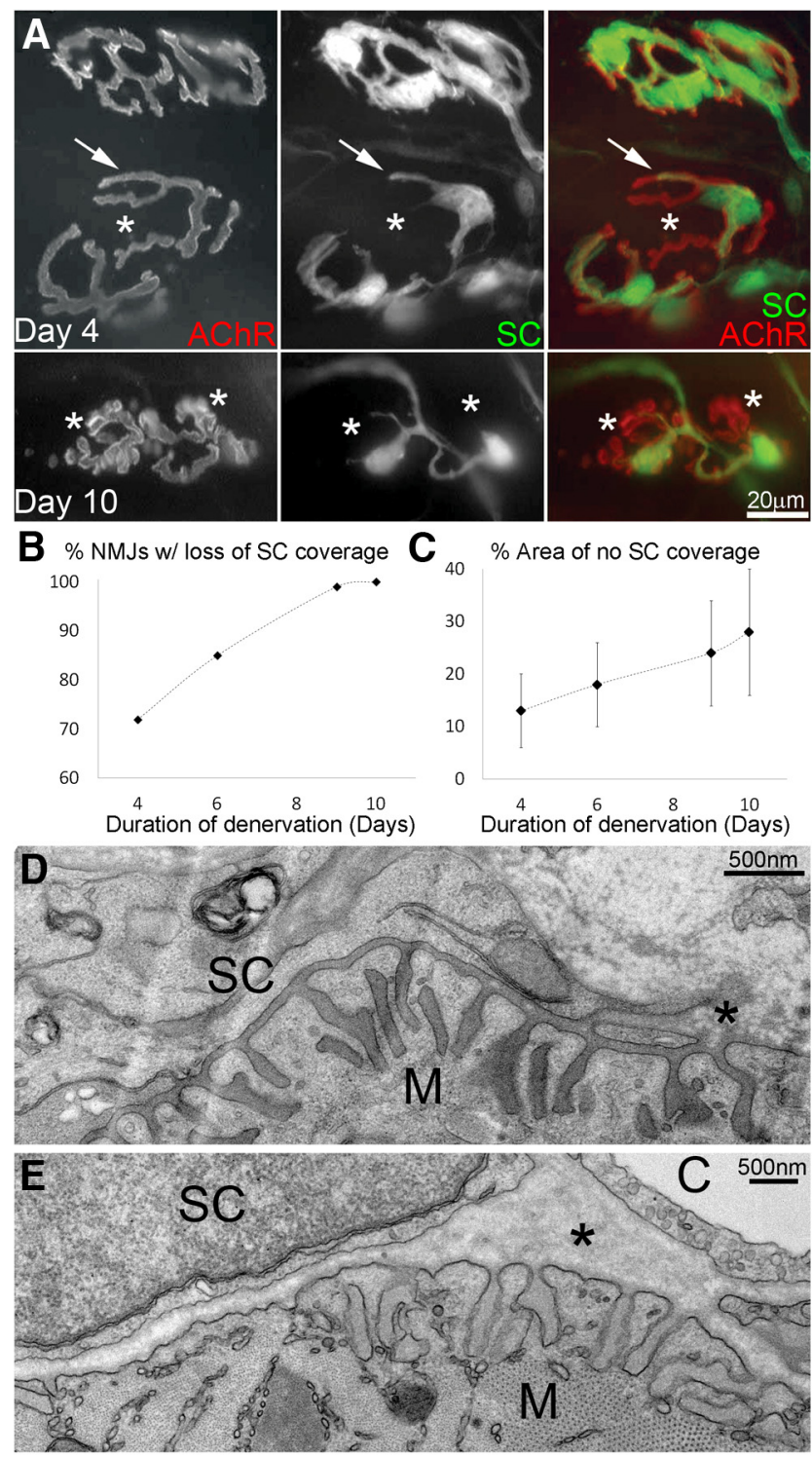

Figure 2. TSCS occupy the synaptic site immediately following denervation but gradually abandon it. $A$, Sternomastoid muscles were denervated by resection of their muscle nerve and then examined in vitro after fixation, $4 \mathrm{~d}$ (top) and $10 \mathrm{~d}$ (bottom) later, i.e., without any reinnervation. In the day 4 images, tSCs (green) remain in association with the AChRs (red) of the upper synaptic site, but have abandoned portions of the AChRs of the lower synaptic site (compare arrows and asterisks). At $10 \mathrm{~d}$ after denervation, the $\mathrm{SS}$ (s have abandoned large areas of the junction (compare asterisks). $\boldsymbol{B}$, The fraction of junctions with loss of $\mathrm{SC}$ coverage of the AChR pretzel increases the longer the duration of denervation times. $C$, The degree of loss of $t S C$ coverage at junctions is correlated with duration of denervation. Vertical lines indicate the SEM of data. $\boldsymbol{D}, \boldsymbol{E}$, Electron microscopy of adult sternomastoid junctions denervated $5 \mathrm{~d}$ earlier. One NMJ shows that $S$ C processes remain very close (within $\sim 50 \mathrm{~nm}$ ) to sites on the muscle containing junctional folds and therefore presumed to contain high densities of AChR. $\boldsymbol{E}$, Example from another junction where such junctional folds are not closely apposed by SCs or their processes (asterisk in $\boldsymbol{E}$ ). Note small portions of the sites in $\boldsymbol{D}$ and $\boldsymbol{E}$ (asterisks) are unoccupied by SCs. M, muscle fiber; C, capillary.

for $5 \mathrm{~min}$. When the sternomastoid was to be imaged, animals were intubated and their respiration driven from a rodent ventilator (Harvard Apparatus). During the collection of images, the respirator was briefly turned off so that respiratory movements momentarily ceased and images could be taken with minimal movement of the muscle. The use of such a respirator was unnecessary for experiments involving the soleus.

The endplates near the center of the muscle fibers were imaged through lactated Ringer's solution with Zeiss water-immersion objectives $(10 \times 0.3 \mathrm{NA}, 40 \times 0.75 \mathrm{NA}, 63 \times 0.8 \mathrm{NA})$ using a Zeiss Axiotech
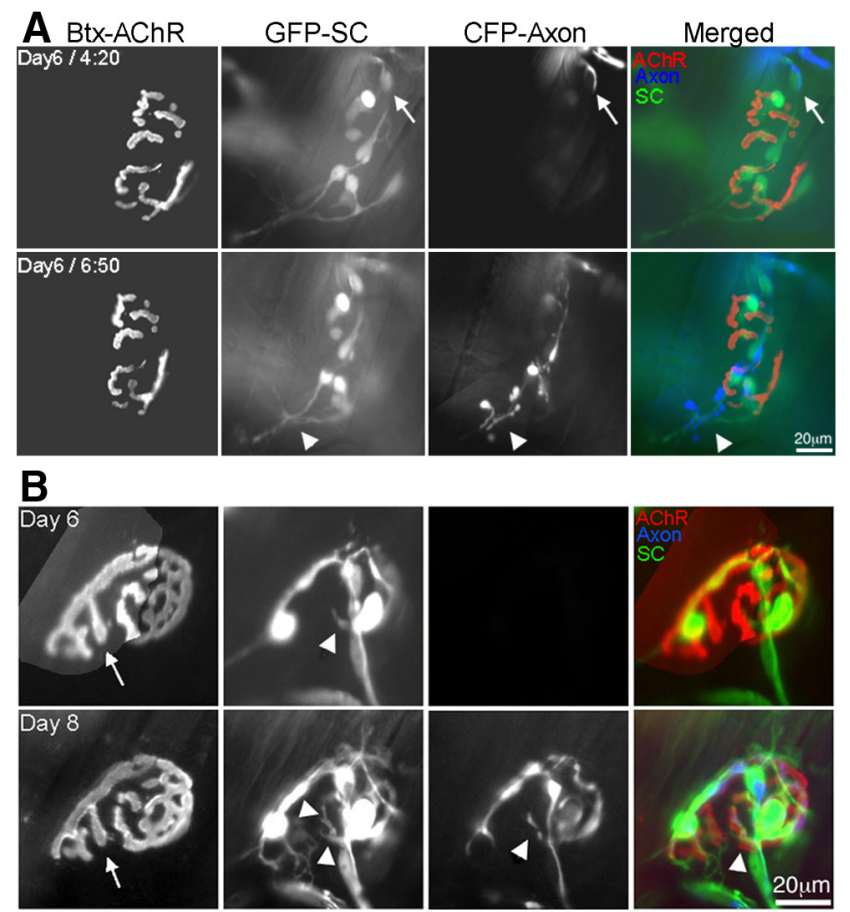

Figure 3. Axons reinnervate synaptic sites by initially following $S C$ processes. $A$, A synaptic site in a sternomastoid muscle vitally imaged twice $2.5 \mathrm{~h}$ apart during the early stages of reinnervation $6 \mathrm{~d}$ following nerve crush. In the first images (Day 6/4:20) SCs (GFP image and green in merged image) incompletely cover the AChRs (red in merged). A regenerating axon (blue in merged) is just entering the top of the synaptic site by following the endoneurial tube (arrow). By the time of the second image (bottom row), the axon has followed some of the SC processes, growing all the way to the other side of synaptic site, even extending beyond the site, forming an escaped fiber (arrowhead). Note that the escaped fiber follows an SC process present in the image made $2.5 \mathrm{~h}$ earlier. Therefore the axon, at least initially, follows $\mathrm{SC}$ s rather than the AChRs. $\boldsymbol{B}, A$ synaptic site in sternomastoid muscle denervated by nerve crush. The first set of images was acquired vitally on day 6 , before the return of innervation. The CFP-axon section here is intentionally black; no axon was present and no picture was taken. The second set of images was acquired vitally on day 8, soon after the return of a regenerating axon over the endoneurial tube from the bottom. The regenerating axon appears to follow the $\mathrm{SC}$ processes present before reinnervation, but in addition, there apparently is some stimulation of $\mathrm{SC}$ growth within the synaptic site so that new processes (compare arrowheads) are present over AChRs that were not present $2 \mathrm{~d}$ earlier. The arrows indicate an area of the receptors that has no $\mathrm{SC}$ processes.

microscope and a MicroMAX $5 \mathrm{MHz}$ cooled CCD camera or Nikon water-immersion objectives $(10 \times 0.3 \mathrm{NA}, 40 \times 0.8 \mathrm{NA})$ using a Leica DMR microscope and a CoolSnap HQ CCD camera (Roper Scientific) controlled by IP Lab software (Scanalytics) on Mac computers. Illumination from a $100 \mathrm{~W}$ mercury lamp was attenuated $50-95 \%$ using neutral density filters. Various filters and dichroics (Chroma) were used for the different fluorophores: rhodamine (535/50x, 565LP, 610/75m); GFP (495/30x, 515LP, 535/30m); CFP (436/20x, 455DCLP, 470/40m). The filters and dichroics for GFP and CFP were designed to reduce the crossover in fluorescence excitation and emission for these two fluorescent proteins at some cost of weaker signal. However, they worked very well except for cases where the GFP fluorescence was much brighter than that for CFP, which happened rarely in our experiments. In a few experiments animals expressing S100 promoter-driven YFP (Zuo et al., 2004) and thy- 1 driven CFP were used. In these cases, Alexa 594 Btx (Invitrogen) was used to label AChRs, and the filter and dichroic combinations were as follows: Alexa 594 (580/20x, 595LP, 630/60m); YFP (500/20x, 515LP, 535/30m); CFP (436/20x, 455DCLP, 470/40m). After images were collected, the gastrocnemius muscle or the salivary glands were moved back into position and the wound closed using 6-0 suture. The animal was allowed to recover and then returned to its home cage. 
Confocal microscopy and analysis

NMJs in fixed tissues were imaged with an oil-immersion objective $(60 \times$, 1.35 NA) using an Olympus FV1000 confocal microscope. AChRs were labeled with Alexa 594-conjugated Btx. Receptor area was measured with MetaMorph software (Molecular Devices).

\section{Electron microscopy}

The sternomastoid muscle of a young adult mouse was denervated by section of the muscle nerve and $5 \mathrm{~d}$ later the muscle was prepared for electron microscopy. NMJs were located, sectioned, and examined using procedures described previously (Smith et al., 2013).

\section{Immunohistochemistry}

For some experiments, the animal was killed and the muscle was removed after the final imaging session, fixed in $4 \%$ paraformaldehyde in PBS, pH 7.4, for 40 min. After rinsing in PBS, a thin layer of fibers was then dissected from the surface of the muscle and mounted in fluorescence mounting medium. The same endplates imaged in vivo were located in vitro based upon the labeling of AChR of the junction of interest and the surrounding junctions. In some cases junctions were also immunostained for the synaptic vesicle antigen SV2 using a mouse monoclonal antibody (Developmental Studies Hybridoma Bank) with a secondary antibody conjugated to Cy-5.

Numerical data are presented as mean \pm SEM.

\section{Results}

\section{Fluorescent protein expression itself does not alter} muscle innervation

Generation of transgenic mice expressing both GFP in their SCs and CFP in their motor neurons allows imaging of SCs, motor axon terminals, and postsynaptic AChRs (via application of fluorescently tagged Btx, which binds to AChRs with high specificity and affinity) at the NMJ in living animals by fluorescence microscopy. However, the usefulness of these animals would be limited if either transgene expression or imaging itself induced abnormalities in axons, synapses, or muscle fibers. Previously, junctions imaged once in double transgenic adult animals appeared similar in size, complexity, and shape as junctions in wild-type animals stained acutely with synaptophysin, neurofilament, and Btx (Zuo et al., 2004). To extend these observations, we performed a number of control experiments.

First, images were collected from 55 NMJs ( 31 in five sternomastoid and 24 in five soleus muscles) in doubly transgenic mice ( $\sim 2$ months old). When the same junctions were imaged again $30 \mathrm{~d}$ later, none of the synaptic sites showed changes in the axon terminal branching pattern, the direction from which the axon entered the synaptic site, or a production of nerve sprouts. Furthermore, with a few exceptions noted below, there was no change in the number or position of SC somata visible over the junction. All but five of the junctions (three in sternomastoid and two in soleus) showed no change in the patterns of AChR-rich postsynaptic gutters that lay beneath the nerve terminal branches (Fig. 1A). These observations suggest, in agreement with previous observations (Balice-Gordon and Lichtman, 1990), that the NMJs in adult mice generally do not change their gross, light microscopic morphology over such time periods, and here we extend these observations to the synaptic glial coverings. We did, however, observe changes in a small number of the junctions. Five of the junctions showed a minor loss of AChR areas amounting to $<5 \%$ of the total area. In three cases, the sites lost were located at the point where the nerve entered the synaptic site (Fig. $1 B$ ). As suggested previously (Balice-Gordon and Lichtman, 1993), these losses appeared to occur at this entry point as an SC intruded into areas of the nerve terminal branches that were previously synaptic. In fact, in one case, an extra SC appeared at the
Table 1. Loss of SC coverage of AChR sites in sternomastoid muscles following different periods of denervation

\begin{tabular}{lllll}
\hline $\begin{array}{l}\text { Duration of } \\
\text { denervation } \\
\text { (days) }^{a}\end{array}$ & $\begin{array}{l}\text { \# Muscles } \\
\text { examined }\end{array}$ & $\begin{array}{l}\text { with loss of } \\
\text { SC coverage }\end{array}$ & $\begin{array}{l}\text { Degree of loss of } \\
\text { SC coverage, \% of } \\
\text { total AChR area } \\
\text { (mean } \pm \text { SEM) }\end{array}$ & $\begin{array}{l}\text { Range of loss of SC } \\
\text { coverage of synaptic } \\
\text { site (\% of area) }\end{array}$ \\
\hline 4 & 6 & $72 \%(n=125)$ & $13 \pm 7 \%$ & $3-32 \%$ \\
6 & 4 & $85 \%(n=112)$ & $18 \pm 8 \%$ & $3-37 \%$ \\
9 & 2 & $99 \%(n=101)$ & $24 \pm 10 \%$ & $5-50 \%$ \\
10 & 2 & $100 \%(n=93)$ & $28 \pm 12 \%$ & $12-70 \%$ \\
\hline
\end{tabular}

${ }^{a}$ The durations were chosen to correspond to the earliest reinnervation detected following different methods of denervation.

site of AChR loss (Fig. 1B, arrowhead) and this SC had the staining characteristics of a myelinating cell (lighter GFP labeling with nucleus located adjacent to the nerve).

We next extended these observations to include more viewing times to test whether the imaging procedure produced alterations in innervation. Fifteen synaptic sites in four adult soleus muscles were imaged a minimum of four to five times over the course of $30 \mathrm{~d}$. Only one of these showed a single, minor change in the receptor area. We conclude therefore, that NMJs can be observed repetitively in transgenic animals expressing GFP and its variants in SCs and motor neurons, as in the experiments reported below, without induction of changes in the synapses as a consequence of either imaging or transgenesis.

\section{Terminal SCs remain apposed to the synaptic site and cover AChRs immediately following denervation but gradually abandon portions of the synaptic site}

Immediately following denervation, $\mathrm{tSCs}$, in addition to extending processes into perijunctional space (Reynolds and Woolf, 1992; Son and Thompson, 1995; Kang et al., 2007), remain in position covering the AChRs in the muscle fiber membrane (Fig. $2 A$, top). With longer times of denervation, however, this association deteriorates such that some receptor areas within the junction are no longer occupied by SCs or their processes (Fig. 2A, asterisks). To quantify the extent of this change, we denervated soleus and sternomastoid muscles by nerve resection to prevent reinnervation and then examined the extent of receptor coverage (Btx fluorescence) by SCs (GFP fluorescence) at NMJs after various periods of denervation. To obtain measurements from a large number of synaptic sites, the muscles were removed from the animals and examined in vitro rather than vitally. In soleus muscles $(n=3)$, some portion of the AChR site was devoid of SCs at $\sim 62 \%$ of the 80 junctions examined $4 \mathrm{~d}$ after nerve resection. At junctions with such loss, an average of $16 \pm 1 \%$ (SEM) of the junction was not covered by tSCs $(n=26)$. When examined at various time points in sternomastoid muscles, the loss of SC coverage following denervation was also correlated with the duration of denervation. NMJs with any loss of SC coverage increased from $72 \%$ after $4 \mathrm{~d}$ to $100 \%$ following $10 \mathrm{~d}$ of denervation (Fig. 2B). For those junctions that lost coverage, the extent of loss increased from $13 \%$ after $4 \mathrm{~d}$ of denervation to $28 \%$ following $10 \mathrm{~d}$ (Fig. 2C), and the variation in loss became more extensive (Table 1). We also observed changes in SC coverage of synaptic sites during vital imaging experiments presented below. Such changes in coverage were not observed in control experiments of repeated imaging. We do not believe these changes are explained by damage induced by the denervation procedure, because other than a manipulation to the nerve this procedure is the same as for the vital imaging described below.

These observations on the disposition of the tSCs are all based on fluorescence microscopy. Given the resolution of this tech- 
nique, the small distances expected between the cells, and the possibility that small processes would not be detected because they contain, volume-wise, small amounts of GFP, we sought to confirm our observations with electron microscopy. We examined sternomastoid muscles denervated by nerve cut $5 \mathrm{~d}$ earlier. Some denervated sites, identified by the presence of junctional folds, remained covered by SC processes that were located $\sim 50$ $\mathrm{nm}$ from the muscle fiber (Fig. 2D). More common, however, was to find coverage by SC processes that were located at a larger distance from the muscle fiber membrane (Fig. 2E). At other sites we identified junctional folds where no SCs or SC processes were seen in the section (Fig. $2 D, E$, asterisks). One common feature to all these views was the presence of many, often bundled, basal lamina-wrapped SC processes above the synaptic site, suggesting, as expected, a considerable remodeling of the SC itself. We conclude that the absence of fluorescence at some denervated sites is consistent with the ultrastructural findings and can report in a reliable manner the extent of tSC coverage of the synaptic site. Junctions in normal animals of similar age show SC coverage of the terminals above synaptic sites (Smith et al., 2013).

\section{Regenerating axons deploy within the junction by first following SC processes}

In the peripheral nervous system, injured motor axons can regenerate and reform synapses, even with the same muscle fibers (Nguyen et al., 2002) as long as nerve sheaths/endoneurial tubes are maintained at the site of damage (Gutmann and Young, 1944; Rich and Lichtman, 1989). These regenerating axons arrive at old synaptic sites by following these endoneurial tubes (Young, 1974; Nguyen et al., 2002). As an axon returns to an old synaptic site, it would be expected to encounter tSCs that would occupy a variable portion of the AChRs depending on the length of time the muscle fiber had been denervated (Fig. 2). To examine the behavior of regenerating axons in such cases, we denervated muscles and timed the collection of the first images to occur just before and then during the arrival of axons back at the old synaptic sites. The two sets of experiments performed in sternomastoid muscles showed that the SC configuration that existed before the return of the regenerating axon predicted the direction of growth and branching pattern of the axon as it re-entered the former site. In doing so the terminal branches primarily followed the SC processes within the former synaptic site (Fig. 3). Some exceptions that occur later in the course of reinnervation are dealt with below. The axons even formed "escaped fibers" (Astrow et al., 1994) following SC processes from the junction in preference to growing along AChR gutters that lacked SC coverage (Fig. $3 \mathrm{~A}$, arrowhead). As a consequence of SC guidance, the axon terminal branching patterns, particularly in cases of synaptic sites where AChR gutters were separated from each other by muscle membrane lacking clustered receptors, became altered from the original pattern (Figs. 4, 5, 6). Moreover, while the majority of muscle fibers were reinnervated by an axon growing in the endoneurial tube, some fraction became reinnervated by an axon arriving from a new direction (Table 2). The incidence of the changes in axon terminal branching and the direction of reinnervation varied with the time the muscle remained denervated before regenerating axons returned; changes were more frequent the longer the time of denervation (Table 2). This finding came from imaging the same NMJs before and $30 \mathrm{~d}$ after reinnervation using three different denervation methods: reinnervation began $4 \mathrm{~d}$ following crush of the muscle nerve near the muscle (termed lateral nerve crush), after $6 \mathrm{~d}$ following crush of the muscle nerve more distant from the muscle (termed medial nerve crush), and

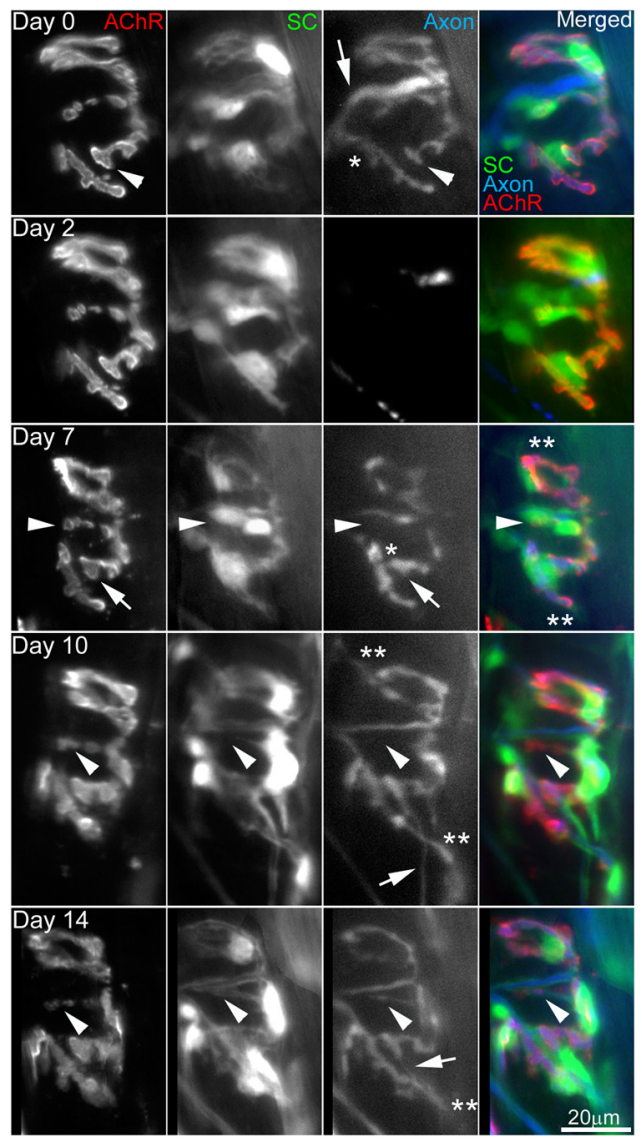

Figure 4. Reinnervation of a synaptic site results in changes in terminal branching pattern and AChR loss. AChRs, tSCs, and axon terminal (red, green, and blue in merged images, respectively) were imaged repeatedly at a NMJ in soleus muscle over the course of $14 \mathrm{~d}$ following nerve crush. The first images (row 1) were collected before nerve crush and show that a nerve entered the synaptic site from the left and gave rise to two branches, one innervating the lower finger of AChRs (asterisk) and the other innervating the remainder of the junction (large arrow). Arrowheads indicate those receptor sites innervated by the upper branch discussed below. The second set of images (row 2) was taken $2 \mathrm{~d}$ following nerve crush and showed that the nerve terminal had almost completely degenerated. On day 7 , a regenerating axon had begun to reinnervate the site, following SC processes. The axon branches initially as before, but a portion of the junction (arrow) previously innervated by the upper branch (see row 1) now is reinnervated by the lower branch (asterisk). Note that two small SC processes had grown away from the junction (double asterisks). 0 n day 10, at least three escaped fibers were growing from the junction; two of them appeared to have followed SC processes grown before day 7 (double asterisks in row 2 and 3) and the third escaped fiber (arrow) was also associated with a SC process grown between the image sessions. A portion of the synaptic site, which lacked SC coverage (arrowheads in row 4), was not occupied by the regenerating axon. AChRs in this area become fainter in the final images taken on day 14 (arrowheads). Two of three escaped fibers found at day 10 had been withdrawn (double asterisks).

after $9 \mathrm{~d}$ following double nerve crush (see Materials and Methods for details). We found, for example, that when reinnervation began $4 \mathrm{~d}$ following nerve injury, all junctions were reinnervated through the original endoneurial tube and only 59\% of these showed changes in the axon terminal branching pattern. On the other hand, $12 \%$ of the junctions were reinnervated from a new direction (i.e., not through the endoneurial tube) and 100\% of the junctions, including those reinnervated through the endoneurial tube, showed some change in terminal branching when reinnervation began at $9 \mathrm{~d}$ (Table 2 ).

We show below cases where some AChR sites abandoned by SCs were never reoccupied by regenerating axons (10 cases). However, we also saw cases where an AChR gutter that was devoid of axon terminal and SC subsequently became innervated 


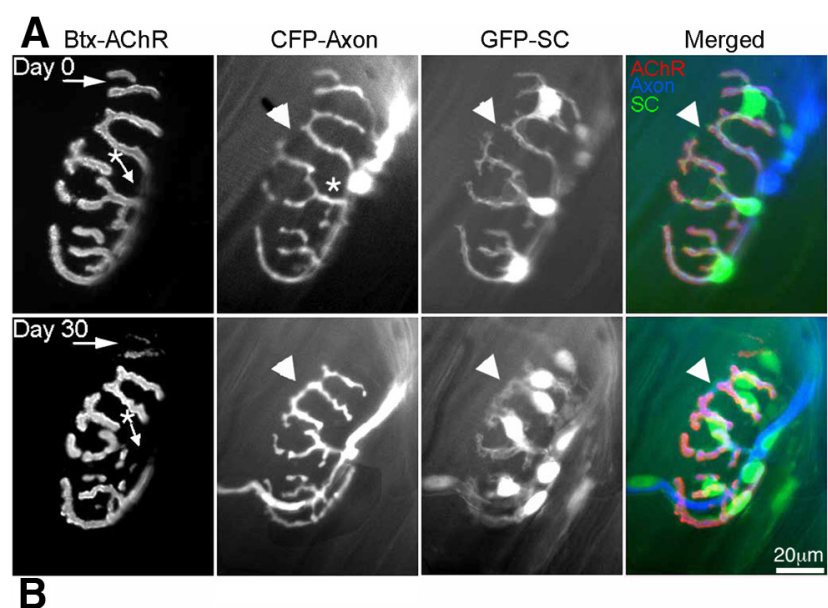

B
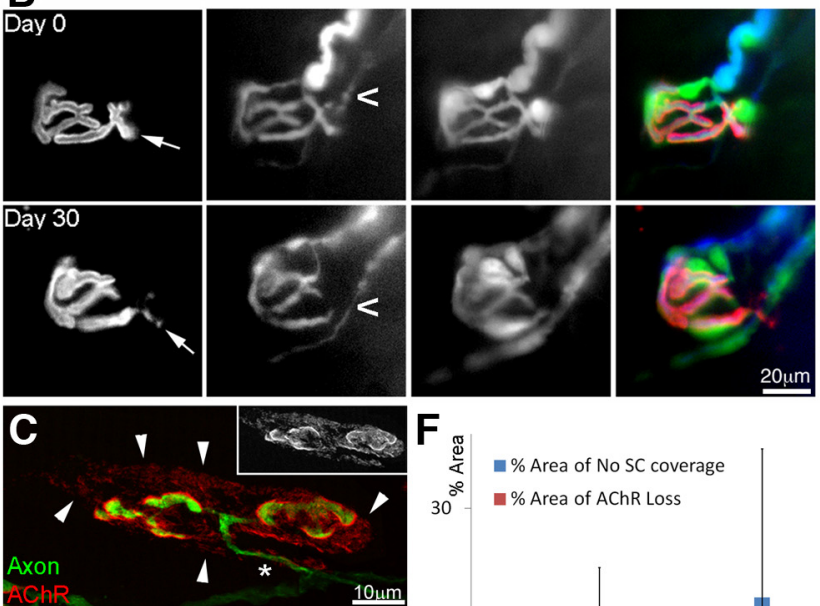

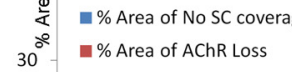
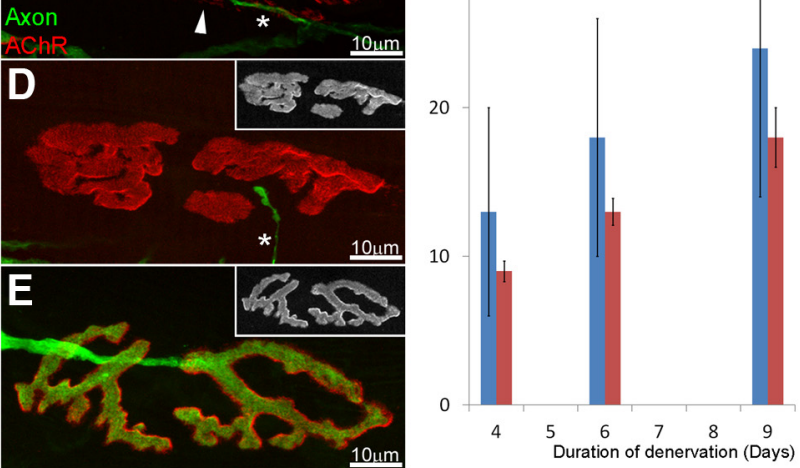

Figure 5. Degree of AChR loss following reinnervation is correlated with duration of denervation. $A, B, A C h R s, t S C s$, and axon terminal (red, green, and blue in merged images, respectively) in the sternomastoid $(\boldsymbol{A})$ and soleus muscles $(\boldsymbol{B})$ were viewed initially immediately before denervation by nerve crush (Day 0 images in each case) and then $30 \mathrm{~d}$ later following reinnervation by nerve crush (Day 30). In each case a single axon is present at the time of the second view and in each case this axon enters from the top right over the same pathway by which the site was originally innervated. All arrows indicate receptor sites that have been lost or are significantly dimmed in intensity of Btx labeling in the second image. In each case of these faint sites there is no nerve terminal branch at the second view. Both junctions underwent a significant change in the branching pattern of the nerve terminal. The arrowheads in $\boldsymbol{A}$ show that a portion of the synaptic site has become reinnervated by a novel terminal branch associated with a novel SC pathway. The arrows with the asterisk indicate the receptor sites that disappeared near the entry point to this junction (asterisk), but there is no obvious change in branching pattern of the axon. $\ln \boldsymbol{B}$ there is an axon $(<)$ passing through the viewed area that has no relation to the synaptic site. $\boldsymbol{C}, \boldsymbol{D}$, Long-term denervation by nerve cut results in greater receptor loss from the site. A junction imaged $35 \mathrm{~d}$ after nerve cut $(\boldsymbol{C})$. The junction has been reinnervated but only partially by an axon (asterisk). Here the color of the axon is presented in green (as also in $\boldsymbol{D}$ and $\boldsymbol{E}$ ). Insets in $\boldsymbol{C}-\boldsymbol{E}$ are AChR-only views. Those areas that were not reinnervated have very faint Btx staining, indicating loss of AChRs (red) at these sites (arrowheads). In contrast in $\boldsymbol{D}$, a junction from the same muscle is just about to be reinnervated (axon marked with asterisk). Here the receptors, even though they lack reinnervation, are of uniform

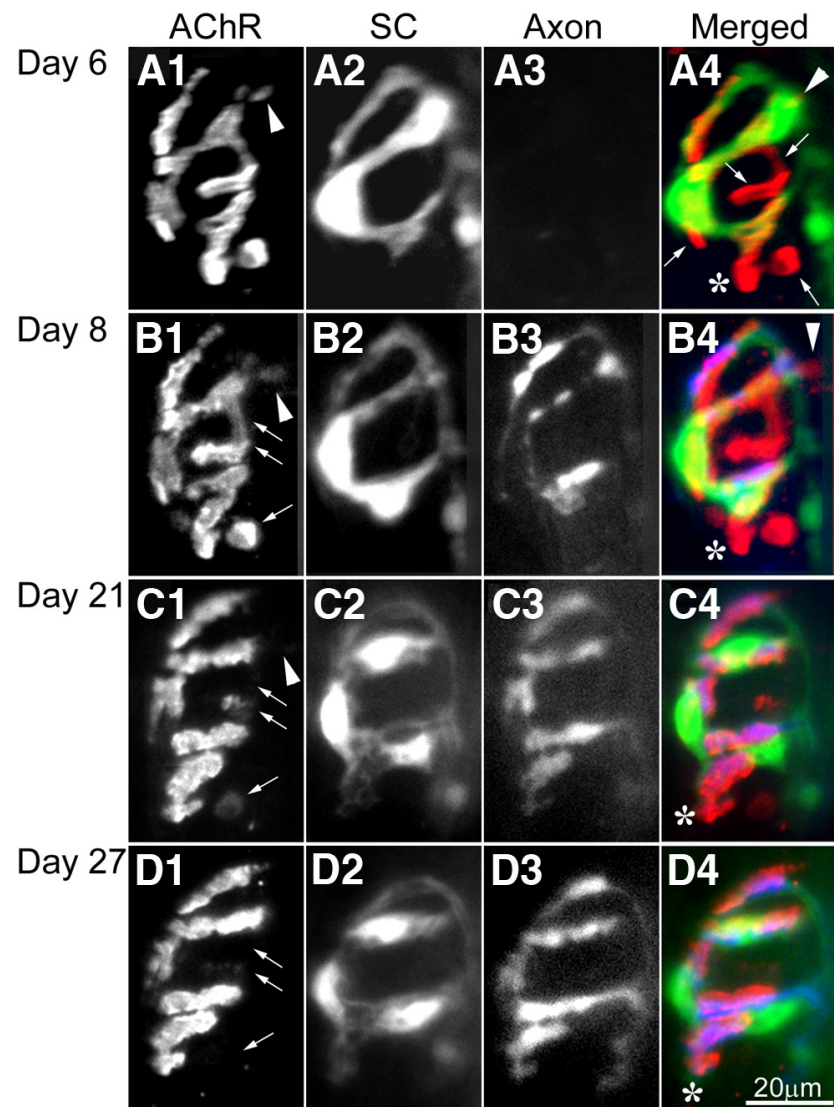

Figure 6. Some AChRs become unoccupied by SCs and are never reoccupied by axon terminals, and are subsequently lost in the course of reinnervation. $\mathrm{AChRs,}, \mathrm{tSC}$, and an axon terminal (red, green, and blue in merged images, respectively) of a NMJ in a soleus muscle imaged repeatedly during reinnervation over the course of $55 \mathrm{~d}$ following nerve crush. Images were taken at days $6,8,10,21,27,40$, and 55 ; only the images from days $6,8,21$, and 27 are shown. When the first images were collected on day $6(\boldsymbol{A} \mathbf{1}-\boldsymbol{A} 4)$, the endplate had not yet been reinnervated. Terminal SCs and their processes only partially occupied $A C h R s$ (receptor areas uncovered by SCs are indicated by arrows and asterisk in $\boldsymbol{A 4}$ ). On day 8 (B1-B4), an axon had regenerated to the junction by growing up the endoneurial tube (most obvious in the lower right side of $\boldsymbol{A} \mathbf{2}$ and $\boldsymbol{B 2}$ ). At this time, the regenerating axon appeared confined to areas occupied by SCs on day 6 . As a consequence, several AChR sites (areas that are only red in B4) were not reinnervated. By day 21 (C1-C4), these AChR sites became faintly labeled or lost (arrows in C1). This loss continued in the images collected on day 27 (D1-D4) and images collected on days 40 and 55 (data not shown). Note, however, that there is one AChR synaptic site not occupied by SCs and not initially reinnervated (asterisk in $B 4$ ) that does become covered by $\mathrm{SC}$ processes and reinnervated and thus escapes elimination. Moreover, one AChR site was covered by an $\mathbf{S C}$ body on day 6 (arrowhead in $\boldsymbol{A} 1$ and $\boldsymbol{A 4}$ ). However, the SC body in $\mathbf{A} \mathbf{2}$ has moved by day 8 and a portion of the receptor area (arrowhead in $B 4$ ) was left uncovered and is not reinnervated by the regenerating axon at day 8 . This receptor area became faintly labeled and disappeared by day 21 (arrowhead $\mathbf{B} 1$ and $\mathbf{C}$ ). Note the addition of a new $\mathbf{S C}$ between day 8 and 21 .

and covered by SCs (seven cases). In some cases we saw short axonal processes extending into gutters where we could detect no presence of a SC (11 cases; Fig. 7); in some cases these processes were covered by SCs at a later time (seven cases); in other cases, these areas were later unoccupied by nerve and their AChR had been lost (four cases; Fig. 7B). In another two cases we saw that reinnervation apparently stimulated the growth of SC processes

$\leftarrow$

intensity. $\boldsymbol{E}$, Control (unmanipulated) muscle showing precise occupation of AChR by the axon terminal branches. The AChRs are uniformly labeled, in contrast to $C$. $F$, The extent of receptor loss (blue) is generally less than the degree of receptor area with no SC coverage (green). Vertical lines indicate the SEM of data for receptor loss. See Tables 1 and 2 for details. 


\begin{tabular}{|c|c|c|c|}
\hline Denervation method & $\begin{array}{l}\text { Lateral } \\
\text { nerve crush }\end{array}$ & $\begin{array}{l}\text { Medial } \\
\text { nerve crush }\end{array}$ & $\begin{array}{l}\text { Double } \\
\text { nerve crush }\end{array}$ \\
\hline $\begin{array}{l}\text { Estimation of start of } \\
\text { reinnervation (days) }\end{array}$ & 4 & 6 & 9 \\
\hline No. of animal used & 9 & 17 & 7 \\
\hline No. of NMJs examined ${ }^{a}$ & $59 / 53 / 49$ & $102 / 70 / 68$ & $40 / 25 / 25$ \\
\hline $\begin{array}{l}\text { \% NMJs with changes in axon } \\
\text { branching pattern }\end{array}$ & $59 \%$ & $70 \%$ & $100 \%$ \\
\hline $\begin{array}{l}\text { \% NMJs reinnervated via } \\
\text { new direction }\end{array}$ & $0 \%$ & $6 \%$ & $13 \%$ \\
\hline$\%$ of NMJs with escaped fibers & $8 \%$ & $27 \%$ & $42 \%$ \\
\hline NMJs with receptor loss ${ }^{b}$ & $59 \% / 1-16 \%$ & $75 \% / 1-23 \%$ & $100 \% / 6-40 \%$ \\
\hline NMJs with $>5 \%$ loss ${ }^{c}$ & $40 \% / 8.7 \pm 0.7 \%$ & $63 \% / 12.6 \pm 0.9 \%$ & $100 \% / 17.9 \pm 2.0 \%$ \\
\hline NMJs with receptor addition ${ }^{d}$ & $18 \% / 1-9 \%$ & $24 \% / 1-22 \%$ & $36 \% / 1-8 \%$ \\
\hline Area of added receptor ${ }^{e}$ & $22.9 \pm 7.8 / 4 \%$ & $36.6 \pm 10.7 / 6 \%$ & $22.3 \pm 5.4 / 4 \%$ \\
\hline
\end{tabular}

${ }^{a}$ Number imaged initially/number relocated $30 \mathrm{~d}$ later/number whose receptor area could be viewed in its entirety en face at both viewings. ${ }^{b}$ Percentage of NMJs with receptor loss/range of receptor loss (\% of total area). 'Percentage of NMJs with $>5 \%$ loss/average loss for NMJs showing $>5 \%$ loss (\% of total area; mean \pm SEM). ${ }^{d}$ Percentage of NMJs with receptor addition/range of receptor addition (\% of total area). ${ }^{e}$ Average added receptor area $\left(\mu \mathrm{m}^{2} \pm \mathrm{SEM}\right) /$ average added receptor area (\% of total area).

that appeared to re-enter previously abandoned gutters and these sites subsequently became reinnervated (compare Figs. 3B, 4).

Endplates lose AChR sites as a consequence of reinnervation During the course of our imaging, we observed a considerable number of cases where NMJs lost AChR sites within a month or so of reinnervation (see Table 2). To get some idea of the extent of this loss, we first conducted a series of experiments in which we imaged axon terminals (via CFP fluorescence), SCs (via GFP fluorescence), and AChRs at junctions in the soleus muscle. We then denervated these muscles by nerve crush and reimaged the same junctions $30 \mathrm{~d}$ later (cf. Fig. 5). We noted any change in the receptor pattern and measured the areas of the receptor sites that were added or lost; the area added or lost was then computed as a fraction of the total area of the AChR site in the original image. Thirteen of 25 endplates in five soleus muscles lost receptor sites that exceeded $5 \%$ of the total initial area of AChRs. These 13 endplates lost on average $17.3 \pm 2.7 \%(\mathrm{SEM})$ of their receptor area. In addition, 2 of these 25 endplates gained receptor areas and this topic is dealt with below.

We next attempted to verify that these losses were not a consequence of viewing these junctions with three different wavelengths of light or to the transgenes expressed in these doubly transgenic mice. We used wild-type mice to make an initial set of images of rhodamine-Btx-labeled receptors at a number of endplates that could be viewed en face in soleus muscles. We then denervated the muscle by crushing the muscle nerve. Thirty days later these same NMJs were viewed again after reapplying rhodamine-Btx. As before, we noted any change in the receptor pattern and measured the areas of the receptor sites that were added or lost. We found that 13 of 27 reinnervated endplates in four soleus muscles lost receptor sites that exceeded $5 \%$ of the total initial area of AChRs. These 13 endplates lost on average $12.6 \pm 1.3 \%$ of their receptor area. In addition 2 of these 27 endplates gained receptor areas; the areas added were 10 and $13 \%$. This addition of receptor sites is considered in the last section.

From these two sets of experiments, we conclude that receptor loss is a common feature of reinnervation following single nerve crush. Approximately half the junctions show loss of receptor areas exceeding $5 \%$ of the total area.

\section{Degree of postsynaptic receptor loss is correlated with the} duration of denervation

Using the sternomastoid muscle and applying various denervation methods that lead to reinnervation after delays ranging from 4 to $9 \mathrm{~d}$, we attempted to determine whether there was any relationship between the loss of AChR sites and the duration of denervation before reinnervation (Table 2), a relationship previously observed by Rich and Lichtman (1989).

In the case of nerve crush at a site close to the muscle (lateral nerve crush), reinnervation began $4 \mathrm{~d}$ later. We imaged initially 59 synaptic sites from nine muscles before denervation and managed to relocate most of these sites $30 \mathrm{~d}$ later following reinnervation. Some of the synaptic sites could not be viewed in their entirety at the second view due to torsion of the muscle fiber on which they were located. We found $\sim 59 \%$ of the synaptic sites had some degree of loss of AChR areas ranging from 1 to $16 \%$ of the receptor area. Considering only sites losing an area $>5 \%$, $\sim 40 \%$ of junctions undergo this degree of loss and the average loss is $\sim 9 \%$ of the receptor area. For crush slightly more distant from the muscle (medial nerve crush) in which reinnervation began 6 d later, we imaged a total 102 synaptic sites from 17 muscles. Of the junctions we were able to reimage and measure in their entirety, $75 \%$ had lost receptor areas and $84 \%$ of these had lost areas exceeding $5 \%$ of the initial area. Following double crush of the sternomastoid nerve, in which reinnervation began $9 \mathrm{~d}$ following injury, we were able to relocate and review en face 18 synaptic sites in seven muscles $30 \mathrm{~d}$ following denervation. All of these sites showed loss of receptor areas. The loss ranged from 6 to $40 \%$ and averaged $18 \%$ (Table 2). Thus, more junctions showed loss of receptor area and the degree of loss was greater the longer the time before nerve return.

We also observed AChR loss in an additional set of sternomastoid muscles in which we performed more frequent imaging in vivo. A total of 30 synaptic sites were successfully imaged several (2-5) times up to $56 \mathrm{~d}$ after medial nerve crush from nine sternomastoid muscles. Among 30 sites, 22 (73\%) lost AChR areas and 3 showed an addition of receptor areas. There were 10 sites that lost receptor areas in which we had a complete en face view at the earliest and latest viewing times. The average loss of area was $13.1 \%$ and ranged between 4.3 and $19.2 \%$. Eight of the sites had lost $>5 \%$ of their receptor area. Thus, a similar loss of receptor area was obtained in more frequent vital imaging.

These results indicate that both the frequency of remodeling of the synaptic site and the extent of this remodeling vary with the time the junction remained denervated before reinnervation occurred. Similar changes related to the length of time the muscle remains denervated have been reported by Rich and Lichtman (1989).

\section{Postsynaptic receptor loss is more severe following prolonged denervation by nerve cut}

To see the effects of denervation periods longer than $9 \mathrm{~d}$, we denervated sternomastoid muscles by cutting the nerve rather than crushing it. The cut ends were closely opposed to each other; this allows NMJs to remain denervated for $\sim 20 \mathrm{~d}$. When we attempted to reimage the same junctions previously imaged before the nerve cut, we had almost no success in relocating the same junctions. The reason is likely that the junctions were so changed that it was impossible to recognize them at the second view. Taking into account all our denervation methods, the success rate in relocating the same junctions decreases when the duration of denervation increased (Table 2). A similar result was reported by Rich and Lichtman (1989). Therefore, instead of 
imaging the same junctions before and after denervation in vivo, we collected confocal stacks of fixed sternomastoid junctions that could be viewed en face in a confocal microscope $35 \mathrm{~d}$ after nerve cut. Among 139 analyzed junctions, 90 junctions (64.7\%) showed $100 \%$ occupation of axon terminals over AChR sites. Seven junctions showed no axon associated with their receptors, which is interpreted as no reinnervation. In the remaining 42 junctions (30.2\%), some receptor area was not fully occupied by axons. Some junctions had receptor areas that were uniformly labeled with Btx, suggesting they had not undergone any differential receptor loss (cf. Fig. 5D). Among 42 partially reinnervated junctions, however, 27 junctions showed brightly labeled receptor clusters overlaid with axon terminals associated with adjoining faintly labeled receptor patches that had no axon present (Fig. $5 C$ ). These faintly labeled receptors would be expected to disappear with time because they are inactive on a muscle fiber activated by the release of acetylcholine at other sites (Balice-Gordon and Lichtman, 1994). We wanted to quantify the severity of junctional changes after nerve cut. Lacking knowledge of the original configuration of the junctions and the degree of atrophy due to long-term denervation, we obtained an estimate of this change by comparing the areas of faintly labeled AChR to the total area of AChR in the same junction (both faint and strong) in 27 junctions (Fig. 5C). Faint receptor areas that we believe will subsequently disappear were on average $19.0 \%$ ( \pm 3.8 , SEM) of the entire AChR area. Considering that some areas may have already become so faint they are undetectable, this ratio may be higher in reality. We also found that the receptors in junctions reinnervated long after denervation were fragmented into small islands. There were $7.0 \pm 0.4$ fragments in reinnervated junctions denervated $35 \mathrm{~d}$ earlier by nerve cut (139 junctions), about twice as many as in junctions in control muscles $(3.3 \pm 0.2,105$ junctions, $p<0.0001$ by $t$ test $)$.

\section{Failure of regenerating nerves to reoccupy portions of} synaptic sites explains a portion of the loss of receptor sites We examined the possibility that failure to reoccupy portions of the synaptic site during reinnervation was predictive of loss of receptor areas. In 20 sternomastoid and 7 soleus muscles, we observed 34 and 20 synaptic sites, respectively, in which we obtained an image before reinnervation, an image within 1-2 d of the beginning of reinnervation, and then subsequent images after reinnervation. For 10 of the synaptic sites in sternomastoid and 7 in soleus, we observed, at the initial image, an area of the AChR site that was not occupied by SCs or their process. Moreover, no nerve or SC process was ever seen above these sites either early or late in reinnervation. In these cases the Btx labeling of the unoccupied site became faint and ultimately disappeared (data not shown). Receptor areas that were separated from other parts of the site were commonly where such loss occurred. For example, in 8 of the 10 cases of loss of receptor areas in sternomastoid muscles, the loss occurred at an isolated site that lacked SC coverage. We also sought additional examples of loss of unoccupied areas by examining synaptic sites where we lacked an image before reinnervation but where we did have an initial image early in their reinnervation (within a day of the arrival of the regenerating axon). We focused our attention on those sites that had an AChR area unoccupied by axons or SCs. We found 29 such endplates in five soleus muscles and subsequent images showed that these areas never became reoccupied (Fig. 6). The AChR at these areas dimmed in their Btx labeling and ultimately disappeared; these areas could not be labeled by application of new Btx.
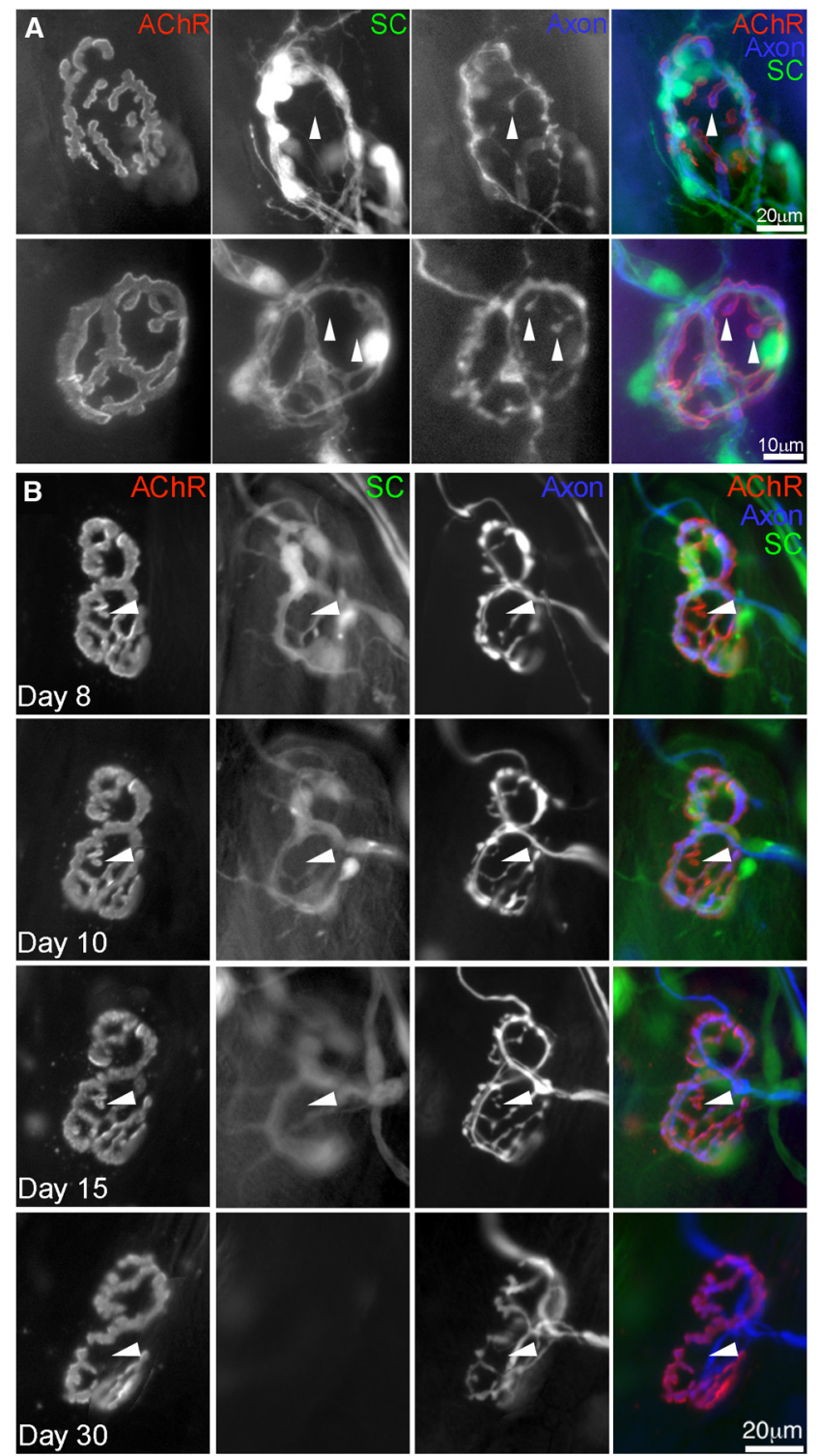

Figure 7. Some junctions with receptor sites reinnervated by axon terminal had no associated SC processes. $\boldsymbol{A}$, Images were collected from junctions in the fixed sternomastoid muscle 7-8d after medial nerve crush. Some parts of receptor sites in these junctions were occupied by axon terminals where no SC process was present (arrowheads). Reinnervated axon terminals were otherwise always with SC processes. $\boldsymbol{B}$, In vivo time-lapse images at the same junctions over a month after median crush showed that some AChR sites abandoned by SCs (arrowheads in Day 8) were temporarily innervated by regenerating axon (arrowheads in Day 10 and 15) but were later unoccupied by nerve and their AChR had been lost (arrowheads in Day 30). NestinGFP expression was greatly diminished in SC at Day $30 \mathrm{~d}$ (see Methods and Materials for details).

As an additional assessment of the possibility that postsynaptic receptor loss at reinnervated synaptic sites is related to their abandonment by SCs, we compared the extent of loss of receptor sites to the loss of SC coverage (Fig. 5F, Tables 1,2). The extent of loss of SC coverage at synaptic sites in the sternomastoid muscles averaged 13,18 , and $24 \%$ after 4,6 , and $9 \mathrm{~d}$ of denervation. In muscles denervated by the three methods, the average extent of receptor loss was 9,13 , and $18 \%$ where reinnervation would have begun at the corresponding times. Thus, the loss of AChR sites is less than would be anticipated based on the extent of loss of SC coverage. If failure of reoccupation of sites by regenerating axons is an explanation for receptor loss, it is clear, as suggested by observations mentioned above, that some receptor sites initially 


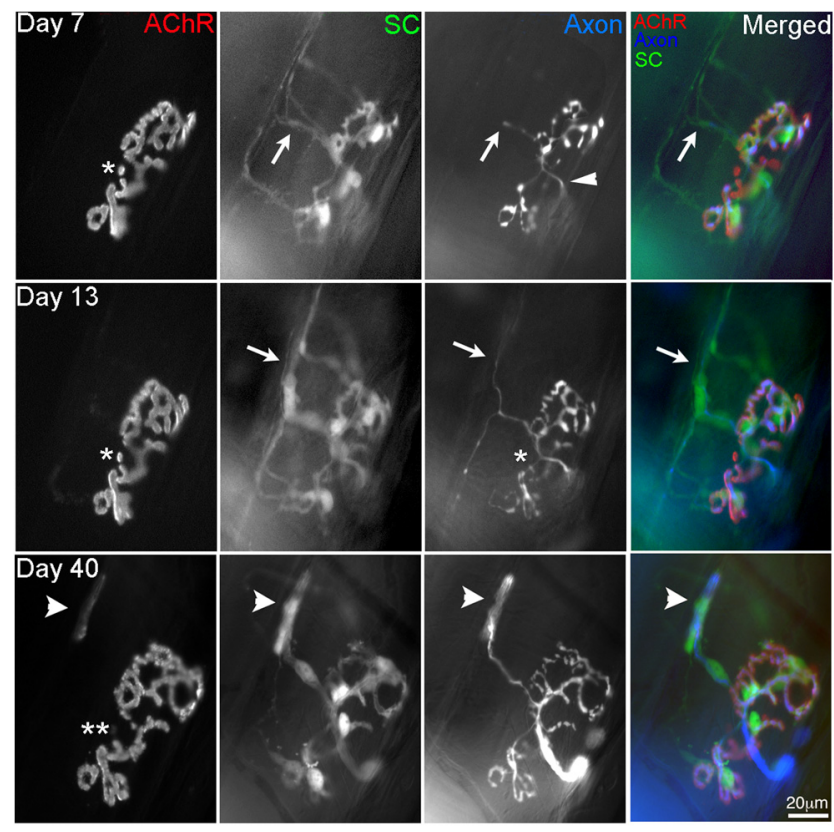

Figure 8. Addition of AChR sites during reinnervation occurs along pathways laid down by $\mathrm{SC}$. A synaptic site in a sternomastoid muscle was imaged five times during the course of reinnervation following nerve crush. The images collected on days 7,13 , and 40 are shown. On day 7 , an axon had regenerated to the synaptic site, entering over the endoneurial tube to the right of the site (arrowhead; the endoneurial tube is mostly out of focus in these images) and had occupied most of the synaptic site. An escaped fiber (arrows) had grown along SC processes that were considerably longer. At day 13 , this escaped fiber was longer still. In the final view at day 40, a new AChR cluster (arrowhead), apparently on the same muscle fiber as the synaptic site, appeared along the course of this escaped fiber. A small portion of the junction indicated with the asterisk was not covered by either $\mathrm{SC}$ process or axon at day 7 and this AChR site became very faint (double asterisks).

unoccupied by the nerve and SCs are subsequently reoccupied (cf. Figs. 3B, arrowhead, 7).

To examine whether the loss of AChR areas requires reinnervation of some sites and the absence of innervation of other sites, we conducted another set of experiments. In two soleus muscles we observed 10 synaptic sites before and after nerve crush, and found two sites that had a portion of their AChR area unoccupied by nerve $\sim 13 \mathrm{~d}$ following the beginning of reinnervation. We then denervated the muscle again by resecting the nerve. We found that the sites not reoccupied following nerve crush that would have been expected to be subsequently lost persisted without loss at least for another $35 \mathrm{~d}$ following nerve resection. These observations suggest, not surprisingly given the results of BaliceGordon and Lichtman (1994), that the loss of these receptor sites requires the disparity in activation of occupied and unoccupied receptor sites by the nerve.

\section{Addition of new AChR sites following nerve regeneration}

In addition to loss of AChR sites, we also observed, at a lower frequency, instances where new AChR clusters were added after nerve regeneration (cf. Fig. 8). In sternomastoid muscles denervated by the three different types of nerve lesions, on average $21 \%$ of the synaptic sites added new receptor areas, with the addition ranging from 1.1 to $11.5 \mu^{2}$ (Table 2). Of the total 32 cases of addition observed, all but 3 occurred in concert with loss of receptors elsewhere in the synaptic site.

Addition of new AChR sites was also observed in sternomastoid and soleus muscles during repeated vital imaging during reinnervation following nerve crush. At 34 and 27 synaptic sites
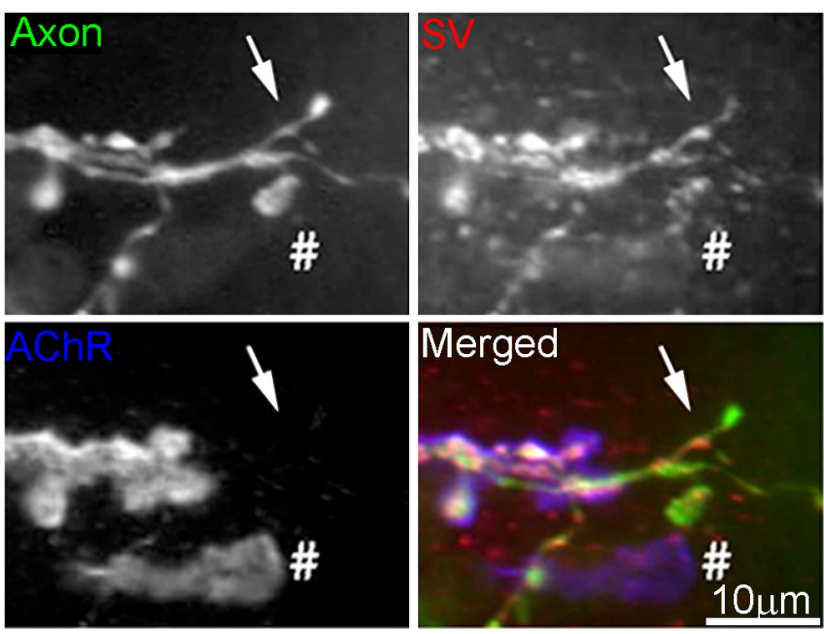

Figure 9. Synaptic vesicles are present in sprouts from reinnervated junctions. Images were collected from a reinnervated NMJ immunostained with antibody to SV2 to label synaptic vesicles. The tips of escaped fibers (arrows) are labeled by SV2 antibody. Axon terminal is green, $A C h R s$ are blue, and SV is red in the merged image.

in 20 sternomastoid and 14 soleus muscles, respectively, we were able to image the endplates both before and 20-30 d following nerve regeneration. We observed five and four cases of new receptor addition, respectively. On average, the addition of receptor area in soleus, when it was found, was $13.9 \pm 3.1 \%$ of the initial synaptic area. These added AChR clusters were always associated with SC processes and nerves. Moreover, in two of these cases, we found that AChR addition occurred along an escaped fiber following its formation (Fig. 8). These results suggest that AChR addition occurs following the formation of escaped fibers guided by SC processes. These additions were generally small in size and we did not follow their fate for long periods of time. However, they did not form obvious pretzels.

In this regard it is interesting to note that of the 33 sternomastoid junctions discussed immediately above, 21 of them had escaped fibers and 5 of these were found to be labeled by antibodies to SV2 (Fig. 9). This suggests that the sprouts that are found to form new synaptic sites in many cases possess the synaptic vesicles that would be required for synaptic transmission. This situation appears like that in the neonate where synaptic vesicles are found along axonal branches within the muscle and are not confined just to synaptic contacts (Lupa and Hall, 1989).

\section{Discussion}

Our study, in agreement with Rich and Lichtman (1989), shows that remodeling of neuromuscular synapses and their postsynaptic receptor areas is more substantial when reinnervation is delayed following injury to a peripheral nerve. Our study addresses the cause of this remodeling. Rich and Lichtman (1989) suggested that the competition between axons reinnervating the same junction leads to this remodeling. They proposed that the difference between rapid reinnervation and slow reinnervation was the degree of polyneuronal innervation of fibers during the reinnervation process. Polyneuronal innervation results from the reinnervation of a junction by escaped fibers arising from a nearby innervated junction that follows SC processes linking the two junctions (Son and Thompson, 1995) as well as to multiple axons reinnervating a junction by growing there via the endoneurial tube. In either case the junction in question can become innervated by more than one axon. As a result of competition between these axons, territories within the junction are aban- 
doned by the losing axon(s) and the AChR at these sites are subsequently eliminated. Since the extent of polyneuronal innervation is determined by the period of denervation, the muscles reinnervated following nerve cut are more dramatically remodeled than those after simple nerve crush. However, in a companion study (H. Kang et al., unpublished observation), we found the number of multiply innervated junctions during reinnervation to be lower than the number of junctions that showed postsynaptic receptor loss. This suggests that there might be reasons for elimination of synaptic sites in addition to competition among multiple axons innervating the same junctions.

SCs at NMJs normally tightly cover the axon terminals that, in turn, are apposed to the postsynaptic receptor sites. We also observed that SCs are located above the receptor sites following denervation. In electron micrographs, the SCs come into close apposition to the surface of the muscle that contains synaptic folds, and therefore were presumably previously synaptic. However, the SCs begin to abandon portions of these sites. Interestingly, the frequency and degree of withdrawal of their processes from synaptic sites is highly correlated with the duration of denervation: the longer the duration of denervation, the more the receptor site is vacated by SCs. Since SCs are powerful guides for regenerating axons (Son and Thompson, 1995), this suggested the possibility that synapse remodeling and receptor loss after reinnervation are related to this abandonment by SCs (Fig. 5).

How does the lack of SC coverage of denervated synaptic sites lead to receptor loss and synaptic remodeling? A clue came from repeated imaging of the same synapses in living animals after nerve injury. Our results suggest that regenerating peripheral axons preferentially follow SC processes when they encounter the denervated synapses after emerging from the endoneurial tube (Fig. 3). After making contact with the receptor surface, regenerating axons seem to be able to reoccupy at least some postsynaptic receptor areas without the guidance of SCs. Subsequently, the SC covers these naked axons. This appears to explain why the total area of lost receptor sites is less than would be anticipated based on the extent of loss of SC coverage (Fig. $5 F$ ). Receptor sites that were isolated from other sites in the junction and that had no SC coverage seemed especially prone to loss, likely because the lack of SCs made axonal growth between the sites unlikely (Fig. 2E). The uninnervated portions of the junction subsequently lose their AChR. The reason for this loss is that other portions of the junction are reinnervated. Balice-Gordon and Lichtman (1994) have shown that active portions of junctions can drive the loss of receptors from inactive portions of the same junction. Our observations showing no loss of receptor areas in the absence of reinnervation (Fig. 5D), nor on occasions where a single axon returns and reoccupies the entire site supports this conclusion. It is important to note that our study focused entirely on the morphology of reinnervation of synaptic sites and that we have no information on the physiology of the reinnervated synapses. Given the high safety factor of NMJs, losses of receptor sites in muscles such as those reported here probably do not change the effectiveness of innervation, although some cases of less effective innervation have been reported in aging and disease (Kelly, 1978; Pratt et al., 2013). Of course our results do not address directly the issue of why SCs abandon the previous synaptic site, but a suggestion is their extension of processes outside the junction (Kang et al., 2007). It is possible that another mechanism explains the failure of these sites to be reinnervated. However, the tight correlation between the location of SC processes and the growth of regenerating axons strongly suggests a connection.
SCs also appear to explain the addition of new receptor sites. When the denervation is prolonged, more junctions showed newly added receptor clusters that are explained by axon growths ("escaped fibers") that extend along SC processes formed in advance of the nerve growth (Fig. 8). Such growth appears at least partially to compensate for the reduction of synaptic area by receptor loss. In the immunolabeling study, the use of the SV2 antibody showed that escaped fibers contain synaptic vesicles (Fig. 9). Thus, it appears that the regenerating escaped fibers would be capable of forming functional synapses upon contact with a receptive surface on the muscle fiber.

In humans, functional recovery following peripheral nerve injuries is often suboptimal (Höke, 2006). This is likely explained by the longer distances required for regenerating axons to reach their targets and, consequently, the longer times required for regenerating axons to arrive and reoccupy denervated junctions. We have shown here that prolonged denervation causes a reduction of synaptic area, which likely reduces functional recovery after nerve injury. This tendency is likely even more problematic in aged individuals because axon regeneration is even slower (Verdú et al., 2000; Kawabuchi et al., 2011; Kang and Lichtman, 2013) and muscle strength is already weakened by sarcopenia (Narici and Maffulli, 2010). Moreover, aged NMJs are very fragmented (Valdez et al., 2010; Li et al., 2011). This means that more receptor areas would be predicted to disappear upon reinnervation as observed in this study because of discontinuities among the receptor sites.

Similar results to those reported here have been found in muscles of the frog. In contrast to the case in mice where the junctions appear stable through early adulthood (Balice-Gordon and Lichtman, 1990), frog junctions show considerable remodeling with seasons of the year, including regression of nerve terminals and SCs from portions of the synaptic contacts, with subsequent turnover of the AChR at the abandoned sites (Anzil et al., 1984). In addition, there is growth of terminals and SCs and deposition of AChR to establish new synaptic sites. In response to denervation, especially long term, there is abandonment of some portion of the synaptic sites by the SCs (Letinsky et al., 1976, Krause and Wernig, 1985). During reinnervation there can be precise reoccupation of the original synaptic site, but there are also cases where the regenerating axon fails to extend into and reoccupy all of the old synaptic sites (Astrow et al., 1996). These sites lose AChR (Grinnell and Do, 1991). In contrast to rodents, the SCs at frog NMJs begin to grow and extend processes away from the synaptic site only after the return of the nerve (Koirala et al., 2000). To the extent that such growth is the cause of SCs abandoning synaptic sites in mouse muscles, then the frog might be expected to have a generally higher percentage of its synaptic sites faithfully reoccupied in contrast to the mouse.

SCs play roles in recruiting axons to reinnervate denervated junctions through the processes they extend away from the junction in mice. In growing these processes away from the junction they appear to withdraw processes that previously covered axon terminals innervating receptor sites. This withdrawal may require redistribution of materials allowing for fast extension of processes away from the junction, potentially accelerating the return of axons to the junction. This is beneficial for minor injuries such as partial denervation. However, it might be harmful in prolonged denervation because it appears to decrease the actual recovery of synaptic area after reinnervation. One possible therapy for injuries that will leave junctions denervated for some time might be to develop treatments that reduce this growth of SCs away from the junction or that somehow retain their occupation of the denervated synaptic sites. In this regard it is quite curious 
that SCs seem to be at least initially attracted to the synaptic surface of the muscle, a site where other studies have suggested there are repellent components keeping the SCs from intruding into synaptic space (Patton et al., 1998). We also do not understand why this attractiveness changes. A similar attractiveness of the surface of the muscle for SCs appears to occur in early development and then wane (Smith et al., 2013).

\section{References}

Anzil AP, Bieser A, Wernig A (1984) Light and electron microscopic identification of nerve terminal sprouting and retraction in normal adult frog muscle. J Physiol 350:393-399. Medline

Astrow SH, Son YJ, Thompson WJ (1994) Differential neural regulation of a neuromuscular junction-associated antigen in muscle fibers and Schwann cells. J Neurobiol 25:937-952. CrossRef Medline

Astrow SH, Pitaevski V, Herrera AA (1996) Precision of reinnervation and synaptic remodeling observed in neuromuscular junctions of living frogs. J Neurosci 16:5130-5140. Medline

Balice-Gordon RJ, Lichtman JW (1990) In vivo visualization of the growth of pre- and postsynaptic elements of neuromuscular junctions in the mouse. J Neurosci 10:894-908. Medline

Balice-Gordon RJ, Lichtman JW (1993) In vivo observations of pre- and postsynaptic changes during the transition from multiple to single innervation at developing neuromuscular junctions. J Neurosci 13:834-855. Medline

Balice-Gordon RJ, Lichtman JW (1994) Long-term synapse loss induced by focal blockade of postsynaptic receptors. Nature 372:519-524. CrossRef Medline

Blake DJ, Weir A, Newey SE, Davies KE (2002) Function and genetics of dystrophin and dystrophin-related proteins in muscle. Physiol Rev 82: 291-329. Medline

Feng G, Mellor RH, Bernstein M, Keller-Peck C, Nguyen QT, Wallace M, Nerbonne JM, Lichtman JW, Sanes JR (2000) Imaging neuronal subsets in transgenic mice expressing multiple spectral variants of GFP. Neuron 28:41-51. CrossRef Medline

Grinnell AD, Do J (1991) Effect of denervation and regeneration on the stability of junctional ACh receptors in mature frog muscles. In: Plasticity of motoneuronal connections, Vol 5 (Wernig A, ed), pp 151-161. New York: Elsevier.

Gutmann E, Young JZ (1944) The re-innervation of muscle after various periods of atrophy. J Anat 78:15-43. Medline

Höke A (2006) Mechanisms of Disease: what factors limit the success of peripheral nerve regeneration in humans? Nat Clin Pract Neurol 2:448454. CrossRef Medline

Kang H, Lichtman JW (2013) Motor axon regeneration and muscle reinnervation in young adult and aged animals. J Neurosci 33:19480-19491. CrossRef Medline

Kang H, Tian L, Son YJ, Zuo Y, Procaccino D, Love F, Hayworth C, Trachtenberg J, Mikesh M, Sutton L, Ponomareva O, Mignone J, Enikolopov G, Rimer M, Thompson W (2007) Regulation of the intermediate filament protein nestin at rodent neuromuscular junctions by innervation and activity. J Neurosci 27:5948-5957. CrossRef Medline

Kawabuchi M, Tan H, Wang S (2011) Age affects reciprocal cellular interactions in neuromuscular synapses following peripheral nerve injury. Ageing Res Rev 10:43-53. CrossRef Medline

Kelly SS (1978) The effect of age on neuromuscular transmission. J Physiol 274:51-62. Medline

Ko CP, Sugiura Y, Feng Z (2007) The biology of perisynaptic (terminal) Schwann cells. In The biology of Schwann cells (Armati, P ed), pp 72-99. New York: Cambridge UP.

Koirala S, Qiang H, Ko CP (2000) Reciprocal interactions between perisynaptic Schwann cells and regenerating nerve terminals at the frog neuromuscular junction. J Neurobiol 44:343-360. CrossRef Medline
Krause M, Wernig A (1985) The distribution of acetylcholine receptors in the normal and denervated neuromuscular junction of the frog. J Neurocytol 14:765-780. CrossRef Medline

Letinsky MS, Fischbeck KH, McMahan UJ (1976) Precision of reinnervation of original postsynaptic sites in frog muscle after a nerve crush. J Neurocytol 5:691-718. CrossRef Medline

Li Y, Lee YI, Thompson WJ (2011) Changes in aging mouse neuromuscular junctions are explained by degeneration and regeneration of muscle fiber segments at the synapse. J Neurosci 31:14910-14919. CrossRef Medline

Lupa MT, Hall ZW (1989) Progressive restriction of synaptic vesicle protein to the nerve terminal during development of the neuromuscular junction. J Neurosci 9:3937-3945. Medline

Marques MJ, Conchello JA, Lichtman JW (2000) From plaque to pretzel: fold formation and acetylcholine receptor loss at the developing neuromuscular junction. J Neurosci 20:3663-3675. Medline

Mignone JL, Kukekov V, Chiang AS, Steindler D, Enikolopov G (2004) Neural stem and progenitor cells in nestin-GFP transgenic mice. J Comp Neurol 469:311-324. CrossRef Medline

Narici MV, Maffulli N (2010) Sarcopenia: characteristics, mechanisms and functional significance. Br Med Bull 95:139-159. CrossRef Medline

Nguyen QT, Sanes JR, Lichtman JW (2002) Pre-existing pathways promote precise projection patterns. Nat Neurosci 5:861-867. CrossRef Medline

Patton, BL, Chiu AY, Sanes JR (1998) Synaptic laminin prevents glial entry into the synaptic cleft. Nature 393:698-701. CrossRef Medline

Pratt SJ, Shan SB, Ward CW, Inacio MP, Stains JP, Lovering RM (2013) Effects of in vivo injury on the neuromuscular junction in healthy and dystrophic muscles. J Physiol 591:559-570. CrossRef Medline

Reynolds ML, Woolf CJ (1992) Terminal Schwann cells elaborate extensive processes following denervation of the motor endplate. J Neurocytol 21: 50-66. CrossRef Medline

Rich MM, Lichtman JW (1989) In vivo visualization of pre- and postsynaptic changes during synapse elimination in reinnervated mouse muscle. J Neurosci 9:1781-1805. Medline

Sanes JR, Lichtman JW (1999) Development of the vertebrate neuromuscular junction. Annu Rev Neurosci 22:389-442. CrossRef Medline

Schaefer AM, Sanes JR, Lichtman JW (2005) A compensatory subpopulation of motor neurons in a mouse model of amyotrophic lateral sclerosis. J Comp Neurol 490:209-219. CrossRef Medline

Serra A, Ruff RL, Leigh RJ (2012) Neuromuscular transmission failure in myasthenia gravis: decrement of safety factor and susceptibility of extraocular muscles. Ann N Y Acad Sci 1275:129-135. CrossRef Medline

Smith IW, Mikesh M, Lee YI, Thompson WJ (2013) Terminal Schwann cells participate in the competition underlying neuromuscular synapse elimination. J Neurosci 33:17724-17736. CrossRef Medline

Son YJ, Thompson WJ (1995) Schwann cell processes guide regeneration of peripheral axons. Neuron 14:125-132. CrossRef Medline

Valdez G, Tapia JC, Kang H, Clemenson GD Jr, Gage FH, Lichtman JW, Sanes JR (2010) Attenuation of age-related changes in mouse neuromuscular synapses by caloric restriction and exercise. Proc Natl Acad Sci U S A 107:14863-14868. CrossRef Medline

Verdú E, Ceballos D, Vilches JJ, Navarro X (2000) Influence of aging on peripheral nerve function and regeneration. J Peripher Nerv Syst 5:191208. CrossRef Medline

Wigston DJ (1989) Remodeling of neuromuscular junctions in adult mouse soleus. J Neurosci 9:639-647. Medline

Young JZ (1974) Functional recovery after lesions of the nervous system. VI. Conclusion. Functional recovery in vertebrates and invertebrates. Neurosci Res Program Bull 12:273-275. Medline

Zuo Y, Lubischer JL, Kang H, Tian L, Mikesh M, Marks A, Scofield VL, Maika S, Newman C, Krieg P, Thompson WJ (2004) Fluorescent proteins expressed in mouse transgenic lines mark subsets of glia, neurons, macrophages, and dendritic cells for vital examination. J Neurosci 24:1099911009. CrossRef Medline 